\title{
Intrahepatic false aneurysm: A complication of needle biopsy
}

\author{
C. WM COLE, MD, FRCSC, JOHn LORIMER, MD, FRCSC, LORRAINE B. Le GRAND-WESTFALL, MD, FRCSC
}

\begin{abstract}
Two months following intraoperative needle biopsy using a Tru-cut needle, the patient returned with a false aneurysm in the left lobe of the liver. Treatment consisted of complete excision of the lesion by left hepatic segmentectomy. The authors discuss therapeutic options for this unusual entity. Can J Gastroenterol 1989; 3(1):37-39 (Pour résumé, voir page 39)
\end{abstract}

Key Words: Biopsy complication, False aneurysm, Needle biopsy

$\mathrm{N}^{\mathrm{s}}$

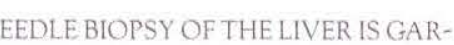
ried out frequently and with a low complication rate whether the procedure is performed percutaneously or intraoperatively. The most common complications of needle biopsy of the liver result from injury to biliary or vascular structures. One of the most frequent complications arising from deliberate puncture of an artery is the formation of a false aneurysm or pulsatile hematoma, but this is very unusual following needle biopsy of the liver. The authors describe such a complication and discuss therapeutic options.

\section{CASE PRESENTATION}

A 78-year-old man was referred with a tender, pulsatile mass in the midepigastrium. He had been well until two months previously when generalized fatigue developed associated with a 30 lb weight loss over a period of two to three months.

Investigations included contrast studies of the gastrointestinal tract and complete hematological assessment; $C T$ scan of the abdomen revealed several filling defects in the spleen and these, together with the patient's clinical symptoms, suggested the possibility of a lymphoma and
Department of Surgery, University of Ottawa. Division of Vascular Surgery, Ottawa Civic Hospital, Ottawa, Ontario; Gatineau Hospital, Gatineau, Quebec

Correspondence and reprints: Dr C. Wm. Cole, Assistant Professor; Division of Vascular Surgery. 1053 Carling Avenue, Ottawa, Ontario KIY 4E9. Telephone (613) 725.4766

Received for publication April 20, 1988. Accepted October 3, 1988 the need for a tissue diagnosis. A laparotomy was performed, the spleen was removed and biopsies were taken of several periaortic lymph nodes. A needle biopsy of the left lobe of the liver was also performed using a Tru-cut needle (2 $\mathrm{mm})$.

Pathological studies revealed the spleen to contain several well healed infarcts, but was otherwise normal. The specimens of lymphatic tissue, as well as the liver biopsy specimen, gave no support to the diagnosis of lymphoma.

Shortly after the laparotomy, blood cultures taken at the time of hospitalization became positive for Streptococcus salivarius which was sensitive to penicillin. Continuous intravenous therapy with penicillin $\mathrm{G}$ was maintained for one month and the patient slowly improved. Noninvasive assessment did not reveal an abnormality of the cardiac valves.

Three weeks after cessation of intravenous antibiotics, the patient was well except for the feeling of tenderness in the mid-epigastrium; this persisted and worsened over the following days. Two months after laparotomy there was a distinct, tender mass in the epigastrium. CT 


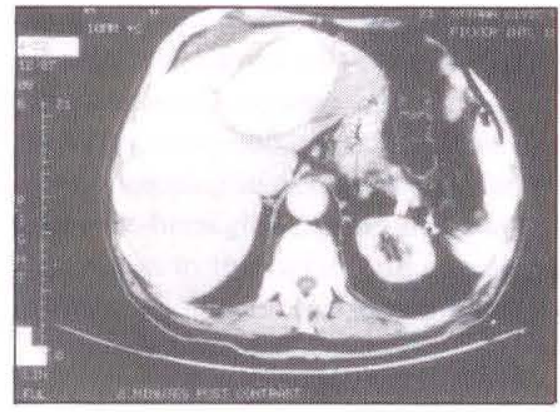

Figure 1) CT scan of the abdomen. The false aneurysm in the left lobe of the liver is outlined by dye enhancement

scan revealed a space occupying lesion in the left lobe of the liver containing material of varying densities, which communicated with the blood circulation as shown by dye enhancement (Figure 1). Angiographic assessment failed to demonstrate the lesion despite passage of the transfemoral arterial catheter into the principal hepatic artery. Duplex scan, however, revealed a single vessel at the base of the lesion and the flow pattern was swirling in character and synchronized with the pulse. This confirmed that the lesion was an intrahepatic false aneurysm.

The history made it seem reasonable

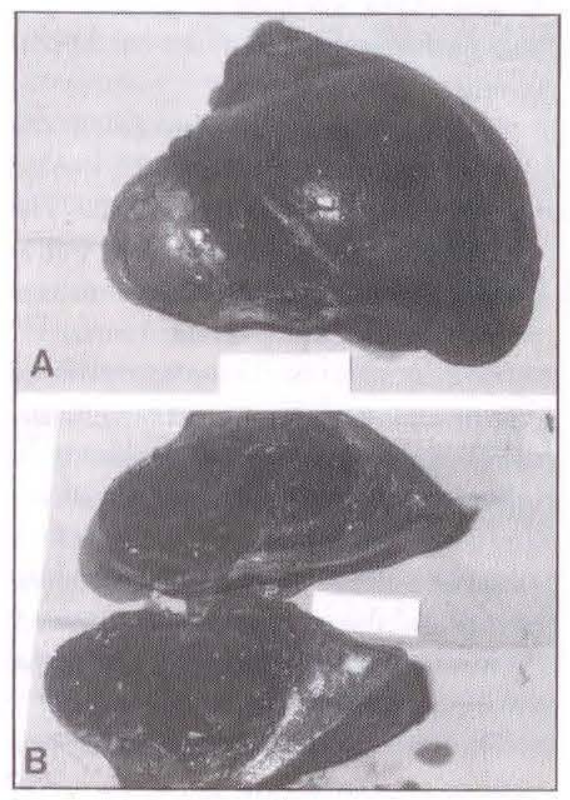

Figure 2) Left lateral hepatic segment. A The intact false aneurysm protruding into the liver substance. A single feeding artery was identified at the time of surgery. B The cut specimen demonstrates the false aneurysm filled with laminated thrombus to suppose that the lesion was the result of a needle biopsy of the left lobe of the liver carried out two months prior to this admission. In view of the patient's recent bacteremia, complete excision was considered to be the ideal method of treatment. A left hepatic segmentectomy was carried out and bacterial cultures of the contained thrombus produced no growth. At the time of surgery the single feeding vessel seen on duplex scan was also clearly identified (Figure 2).

\section{DISCUSSION}

Needle biopsy of the liver is practised widely and has proved to be safe in experienced hands. It is usually carried out as a percutaneous procedure at the bedside, but liver biopsy is also frequently carried out intraoperatively by taking a wedge from the liver edge, or with a biopsy needle of one sort or other to sample deep organ parenchyma. The 'Vim'Silverman needle has been in use since 1938 (1) and while it has been largely replaced by the Menghini needle for the percutaneous technique (2), it remains a popular choice in some centres for intraoperative use (3). The Tru-cut needle is another popular choice for intraoperative biopsies, particularly for the head of the pancreas and the liver. Both the 'Vim'-Silverman and Tru-cut have an outside diameter of $2 \mathrm{~mm}$.

In percutaneous liver biopsy, smaller needles have fewer complications and lower mortality rates. Before 'thin-needle' technique was introduced in the 1960 s, mortality from percutaneous liver biopsy was approximately $0.12 \%$ with the 'Vim' -Silverman needle (4). More recently, with the Menghini 'one second' technique and a needle with an outside diameter of $1.4 \mathrm{~mm}$, mortality is approximately $0.017 \%$ (3). The low risk of the percutaneous procedure using small diameter needles is apparent, however, even with the Chiba needle with an outside diameter of $0.7 \mathrm{~mm}$, occasional complications may be seen (5). There are no comparable data for complications related to intraoperative needle biopsy of the liver.

A false aneurysm may develop after vessel puncture when the hematoma outside the vessel does not compress the puncture site and communicates directly with the lumen. Within the substance of the liver a small needle hole in an artery or vein will usually be sealed by compression of the defect by hematoma and the surrounding liver mass. A larger defect, particularly a rent in the wall of a substantial artery, may not be controlled by compression from the surrounding liver mass. It is unusual for a liver biopsy needle to cause injury of any consequence to neighbouring vascular structures even with needles of $2 \mathrm{~mm}$ calibre. When it does occur it is presumably because an artery or vein has itself been biopsied or cut tangentially, resulting in a much larger defect.

Approximately $7 \%$ of patients studied by liver scan after percutaneous needle biopsy of the liver by Menghini technique have intrahepatic hematomas, but the clinical course of these patients is usually unaffected (6). Anomalous vascular communications are also fairly common after needle biopsy of the liver, but the majority of these run a benign clinical course (7). Communications between blood vessels and bile ducts may complicate needle biopsy procedures and result in hemobilia (8), a serious complication which may require aggressive measures to arrest (9). Intrahepatic hematomas, arteriovenous and vasculobiliary communications are probably at least as frequent after intraoperative needle biopsy which is usually done with one of the larger needles.

The present authors' plan for treatment initially centered around the possibility of embolizing the feeding vessel by angiographic techniques $(10)$ but the feeding vessel could not be identified and this option could not be exercised. The history of bacteremia during a recent hospitalization suggested that complete excision of the lesion would be preferable if laparotomy were to be undertaken. Localization to the left lateral segment made the prospect of excision seem an acceptable technical undertaking for this elderly patient. A false aneurysm arising within the right lobe of the liver would make complete excision a much more complicated procedure and one that might be better avoided in these circumstances. Had the lesion been within the right lobe of the liver an alternative approach might have been to open into 
the false aneurysm directly, as one would a similar lesion in another location, evacuate the laminated thrombus and suture ligate the feeding vessel at the base. Examination of the surgical specimen with its well defined fibrous wall and large cavity filled with laminated thrombus suggests that this technique could have been used successfully in this case.

\section{REFERENCES}

1. Silverman I. A new biopsy needle. Am J Surg 1938;40:671-3.

2. Menghini G. One-second biopsy of the liver - Problems of its clinical application. N Engl J Med 1970;283:582-5.

3. Edmondson HA, Schiff L, Schiff ER Needle biopsy of the liver. In: Schiff L, ed. Diseases of the Liver, 5 th edn. Toronto: Lippincott, 1982:303-31.

4. Terry R. Risks of needle biopsy of the liver. Br Med J 1952;1:1102-5.

5. Redeker AG, Karvountzis GG, Richman

\section{Le faux aneurisme intrahépatique: Une complication de la biopsie à l'aiguille}

Deux mois après avoir subi une biopsie intraopérative à l'aiguille (Tru-cut), la patiente est revenue avec un faux aneurisme du lobe gauche du foie. Le traitement a consisté en une excision complète de la lésion au moyen d'une segmentectomie hépatique gauche. Les auteurs soumettent une discussion sur les options thérapeutiques de cette entité inhabituelle.

RH. Horisawa M. Percutaneous transhepatic cholangiography. An improved technique. JAMA 1975;231: 386-7.

6. Raines DR, Van Heertum RL, Johnson LF. Intrahepatic hematoma: A complication of percutaneous liver biopsy. Gastroenterology 1974:67:284-9.

7. Okuda K, Musha H, Nakajima Y, et al. Frequency of intraheptic arteriovenous fistula as a sequela to percutaneous needle puncture of the liver.
Gastroenterology 1978;74:1204-7.

8. Attiyeh FF, McSweeney J, Fortner JG. Hemobilia complicating needle liver biopsy. Radiology 1976;118:559-60.

9. Spector N. Ligation of the right hepatic artery in hemobilia: Report of a case with recovery. Ann Surg 1957; 145: 244-8,

10. Walter JF, Paaso BT, Cannon WB. Successful transcatheter embolic control of massive hematobilia secondary to liver biopsy. Am J Roentgenol Radium Ther Nucl Med 1976:127:847-9. 


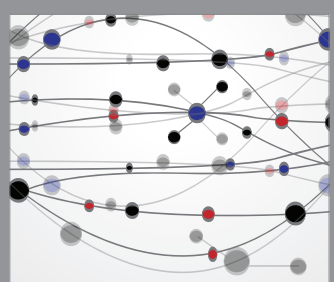

The Scientific World Journal
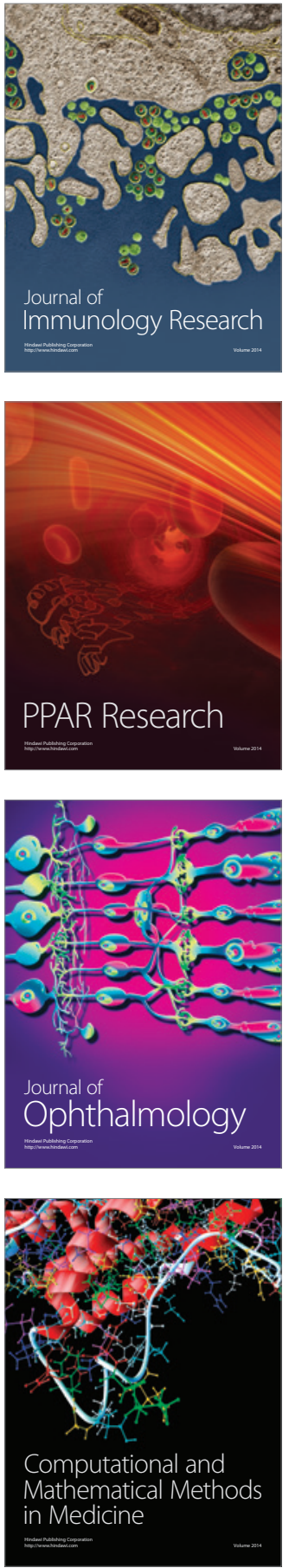

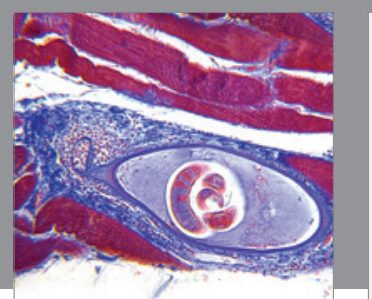

Gastroenterology Research and Practice

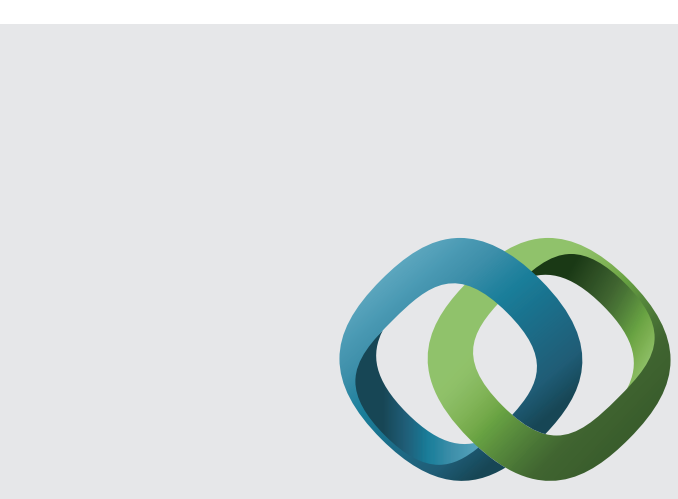

\section{Hindawi}

Submit your manuscripts at

http://www.hindawi.com
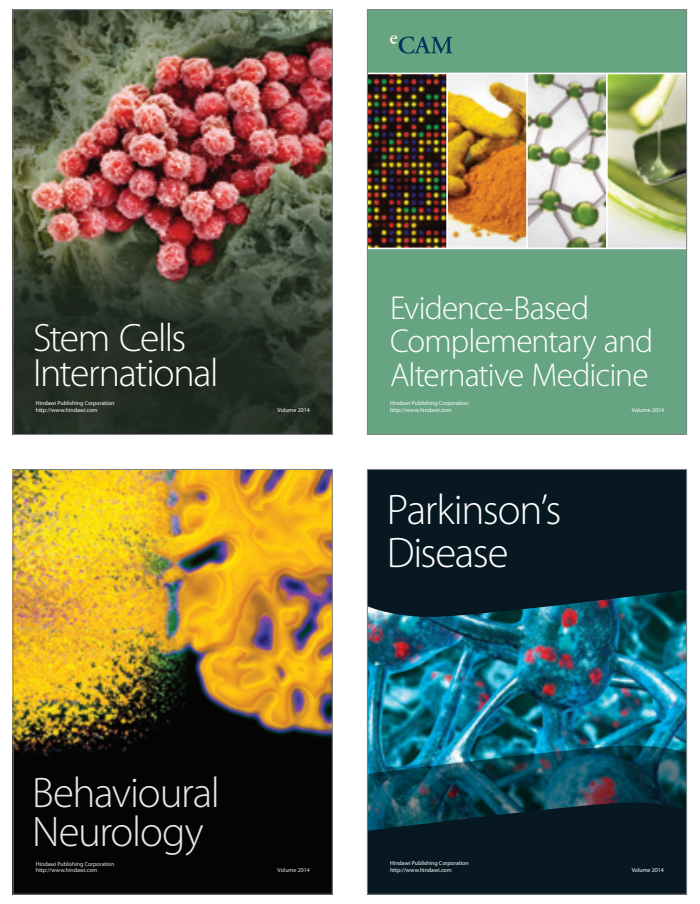
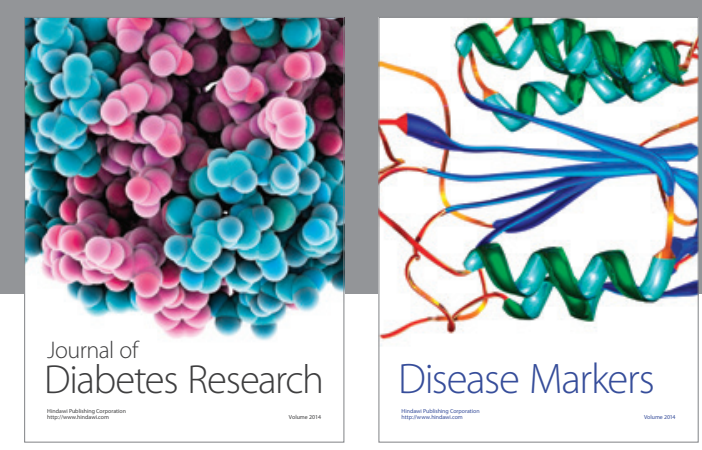

Disease Markers
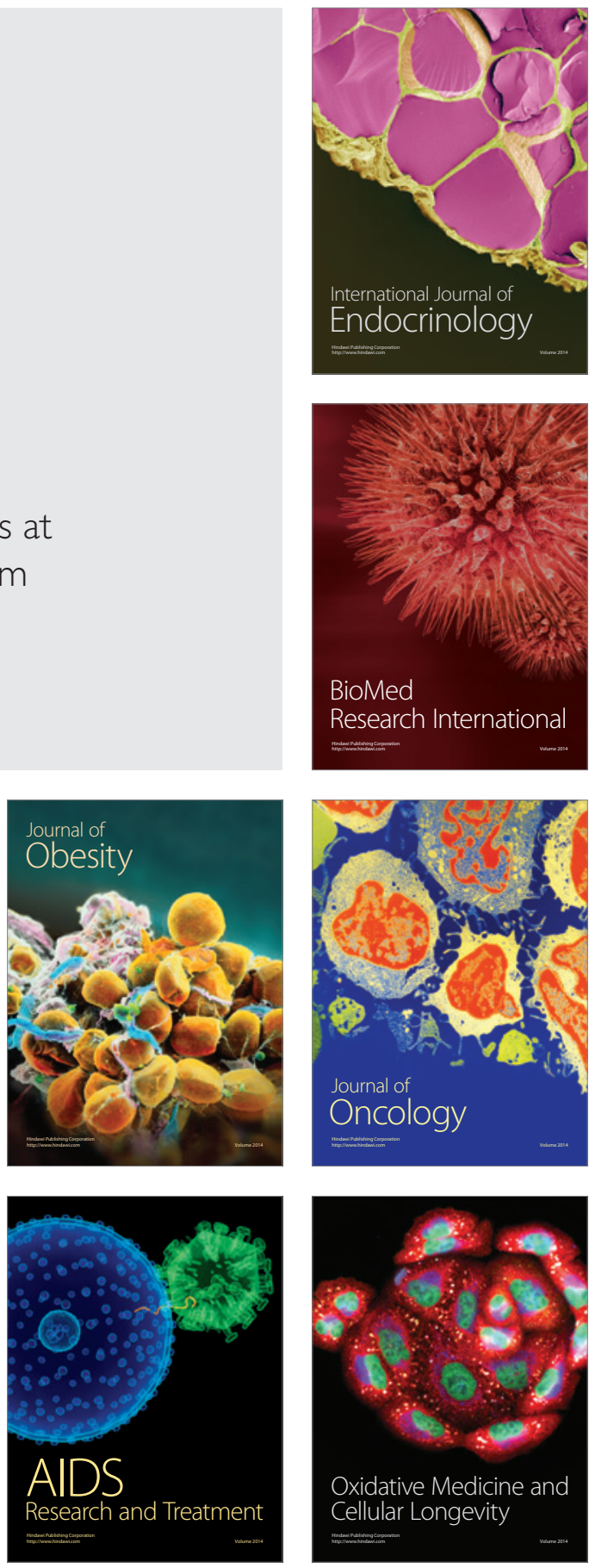